\title{
DEDICATED SOVIET VLBI-NETWORK “QUASAR”
}

\author{
A.M. FINKELSTEIN, G.S. GOLUBCHIN, V.M. GORODETSKY, V.G. GRACHEV, \\ V.S. GUBANOV, A.V. IPATOV, M.N. KAIDANOVSKY, E.I. KORKIN, \\ E.I. NIKOLAEV, S.G. SMOLENZEV, A.A. STOTSKY, N.D. UMARBAEVA \\ AND YA.S. YATSKIV \\ Institute of Applied Astronomy \\ 8 Zhdanovskaya ul \\ 197042 Leningrad \\ USSR
}

\begin{abstract}
The radiointerferometrical network "QUASAR", composed of six dedicated VLBI stations linked via a geostationary satellite channel with the Center of Operations, is under construction in the Soviet Union. It is proposed to construct "QUASAR"-stations abroad, in China, Bulgaria and India. A short review of basic scientific and technical features of the project is given in this paper.
\end{abstract}

In 1988 the USSR Academy of Sciences made a decision to construct a dedicated VLBI network of six radiotelescopes situated over the territory of the Soviet Union (near Leningrad, at Ukraina, North Caucasus, near Ashkhabad,at Lake Baikal, and at Kamchatka peninsula) and linked with the Center of Operations, which is under construction in Leningrad, via a special geostationary satellite channel. It is also considering the possibility of locating other "QUASAR"-stations abroad: in China, Bulgaria and India. The system is named "QUASAR". For the realization and further exploitation of this system, the Institute of Applied Astronomy has been organized by the USSR Academy of Sciences and it involved in this project different groups of scientists and engineers from Leningrad and Moscow.

The network will provide data for precise determination of inertial, dynamical and terrestrial coordinate systems and their mutual orientation as well as for high resolution mapping of cosmic radiosources.

The network will be operated in two modes:

- "Off-Line": using digital magnetic tape recorder with band of $144 \mathrm{MHz}$ per station and

- "On-Line": with the transmission of radiointerferometrical signal from stations to the Center of Operations via a satellite channel with the speed of $4.5 \mathrm{Mbit}$ per second per station.

The technical specifications of the network ate given in Table 1.

Four stations (near Leningrad, at North Caucasus, near Lake Baikal and Ashkhabad) and the Center of Operations are under construction at the present time. The first three stations of the network together with the Center of Operations will be operational in the beginning of 1992 and all six stations in 1994. During this period we are intending to construct and to introduce into the activity some “QUASAR"-stations abroad. The deadline for project realization is 1995. 
Table 1. “QUASAR"-network specifications

1.1 Geometrical characteristics

$\begin{array}{lccc}\text { Network } & \text { Maximum baseline } & \text { Longitude coverage } & \text { Latitude coverage } \\ \text { National } & 6700 \mathrm{~km} & 119^{\circ} & 23^{\circ} \\ \text { International } & 7300 \mathrm{~km} & 119^{\circ} & 48^{\circ}\end{array}$

1.2 Antenna system

Antenna for:

observations of radiosources

observation of navigation satellites

Number

8

$8 \quad 1.3$

Transmission signal via geostationary satellite:

Far East, India, China, Center of Operations

other stations

$4 \quad 12$

monitoring of troposphere electrical characteristics

control of RT32 surface by radioholography

1.3 Receiving system. Radiometers for:

observations of radiosources

observation of navigation satellites

$5 \quad 4$

$8 \quad 1.5$

$2 \quad 0.5$

monitoring of troposphere

control of RT32 surface

Wavelength

$0.7,1.35,3.5,6,13,18 / 21$

19

$1.5,1.0$

2.5

1.4 Time-frequency system

H-maser standard

Primary time synchronization

1.5 Data transmission system

"Off-Line"

"On-Line"

magnetic tapes, $144 \mathrm{MHz}$ per station satellite channel, $4.5 \times 8$ or $9.0 \times 4 \mathrm{Mbit} / \mathrm{s}$

1.6 Control and monitoring system

Central site computer

Number of workstations

"On-Line" system via satellite channel

CM-1425

15

Digital telephone line via satellite channel

1.7 Satellite: Geostatonary satellite GORIzONT with channel bandwith

up-link / down-link frequencies

1.8 Processing system

$10^{-14}-10^{-15}$
20 ns via GLONASS

Correlator (Mark-III format)

number of stations

bandwidth per station

bus type

input data

Mainframe

total RAM

disk memory

Workstations

Software

64 Kbaud

64 Kbaud

channel

$36 \mathrm{MHz}$

$14 \mathrm{GHz} / 11 \mathrm{GHz}$

$\begin{array}{cc}1 \text { Step } & 2 \text { Step } \\ 3 & 10 \\ 120 \mathrm{Mbit} / \mathrm{s} & 288 \mathrm{Mbit} / \mathrm{s} \\ \text { CAMAC } & \text { VME }\end{array}$

magnetic tapes and satellite channels

vAX-6320 cluster

$128 \mathrm{Mb}$

$20 \mathrm{~Gb}$

VS-3100, BESTA-88

VAX/VMS, UNIX

\subsection{Collocation}

Laser ranging systems, gravimeters, seismic and meteorlogical data stations 